\title{
EM PRIMEIRA(S) PESSOA(S): A MEMÓRIA INDIVIDUAL NO CONTEXTO DA ÁFRICA E NA PERSPECTIVA DE NGŨGĨ WA THIONG'O
}

\author{
Marcelo França Marques Cândido ${ }^{1}$ \\ Bernardo Nascimento de Amorim ${ }^{2}$
}

\begin{abstract}
Resumo: No presente artigo, buscamos problematizar algumas constatações que sugerem o excesso do uso da primeira pessoa na literatura contemporânea como responsável por uma possível crise da ficção. Abordamos interseções que o universo literário mantém com o relato memorialístico, de maneira a destacar um tipo de relação que, com as experiências traumáticas do século XX, adquire mais ampla significação, sugerindo tanto uma instância fundamental para os indivíduos que viveram traumas, quanto para as culturas às quais pertencem. Com o foco na experiência africana, trazemos o exemplo de Sonhos em tempo de guerra, primeiro volume da trilogia autobiográfica de Ngũgĩ wa Thiong’o, que afirma a literatura como espaço de reconstrução do sujeito fragmentado a partir do relato autobiográfico, mas não narcísico.
\end{abstract}

Palavras-chave: Memória; Indivíduo; Cultura; Narrativa; Ngũgĩ wa Thiong’o.

Abstract: In the present article, we seek to problematize some findings that suggest the excessive use of the first person in contemporary literature as responsible for a possible crisis of fiction. We approach the intersections that the literary universe maintains with the memorialistic account, in order to highlight a kind of relationship that, with the traumatic experiences of the twentieth century, acquires a broader meaning, suggesting both a fundamental instance for the individuals who lived trauma, as well as for the cultures to which they belong. With the focus on the African experience, we bring the example of Dreams in a Time of War, the first volume of Ngũgĩ wa Thiong'o's autobiographical trilogy, which affirms the literature as a space for reconstructing the fragmented self from an autobiographical but not narcissistic account.

Keywords: Memory; Individual; Culture; Narrative; Ngũgĩ wa Thiong’o.

1 Mestrando do curso de Letras: Estudos da Linguagem da Universidade Federal de Ouro Preto (UFOP) e bolsista da Coordenação de Aperfeiçoamento de Pessoal de Nível Superior (CAPES). E-mail: mac.mfcandido@gmail.com

2 Professor-doutor dos cursos de graduação em Letras e pós-graduação em Letras: Estudos da Linguagem da Universidade Federal de Ouro Preto (UFOP). E-mail: bedeamorim@hotmail.com 


\title{
CONSTATAÇÕES SOBRE UM IMPÉRIO DO EU E SUA POTENCIALIDADE
}

"Provavelmente um dos exercícios mais difíceis na literatura é apagar o eu e imaginar uma terceira pessoa, sua linguagem, suas repetições, suas traições, seu desejo e sua paixão. Sobretudo, imaginar uma distância entre um eu escondido e um personagem" (SARLO, 2017) ${ }^{3}$, escreveu Beatriz Sarlo, em sua coluna no jornal El País. Era agosto de 2017 quando ela publicou este texto, cujo título, "Encerrar o eu em uma lata”, não menos sugestivo que o conteúdo, trazia o esboço de mais uma possível crise. Depois de tantas crises das Humanidades, em que anúncios como "o fim da arte" ou "o fim da história” foram brandidos, agora, uma das maiores críticas literárias argentinas apontava para outra: a crise da ficção.

Seguindo a vida de um tal "Lajos", que, segundo Sarlo, era um ex-combatente austro-húngaro que teria ido para Buenos Aires e se instalado numa comunidade rural, deparamo-nos com uma história de singular ambivalência, operando tanto nos anos 1930 quanto no contemporâneo. É que Lajos - ou melhor, Don Luis, como se deixava ser chamado - não seguia os métodos pedagógicos convencionais e, frequentemente, contava "histórias raras" a seus alunos. Uma delas, em especial, chama a atenção da autora: a da pequena lata de carne em conserva que os combatentes da cavalaria austro-húngara carregavam, sem poder abri-la. Os soldados deveriam zelar por ela, assim como por suas armas, e, ao final, apresentá-las de volta.

Apesar da excentricidade do caso, Sarlo o encontra também nas passagens de Walter Benjamin, mas metaforizado para ilustrar o ofício do escritor:

\begin{abstract}
Deveríamos acostumar escritores a considerar a palavra eu como seu suprimento de comida. Assim como os soldados não podiam tocá-lo antes que passassem 30 dias, nem os escritores deveriam desenterrar o eu antes que os trinta anos sejam completados. Quanto mais cedo eles se voltam para ele, menos entendem seu ofício. (BENJAMIN apud SARLO, 2017) ${ }^{4}$.
\end{abstract}

Fora do senso comum, segundo Benjamin, aquele que se presta à escritura, em especial, ao romance, deveria se manter longe de um relato narcísico sobre a própria vida - pelo menos até que se alcançasse uma certa maturidade. Haveria um tempo certo para colher os elementos autobiográficos, de modo que, antes disso, outros assuntos e personagens deveriam ser a prioridade do escritor. Trata-se de algo semelhante ao que nos diz Serge Doubrovsky, em seu Fils (1977): "Autobiografia? Não, é um privilégio reservado às pessoas importantes do mundo, no crepúsculo de suas vidas, e em belo estilo" (DOUBROVSKY apud PAIVA, 2016, p. 474).

Quando Sarlo comenta a dificuldade de se escrever em terceira pessoa, também está falando sobre esse atalho para a escrita em primeira pessoa. $\mathrm{Na}$ contemporaneidade, regida pelo digital, e de caráter conteudista e empreendedor, cresce a centralidade do indivíduo, mesmo depois de tantos solavancos teóricos atestarem a fragilidade da figura do sujeito -

3 Tradução nossa.

4 Tradução nossa. 
que veio a se mostrar um tanto quanto ficcional, ironicamente. Eventos e redes sociais dão acesso exclusivo ao escritor como indivíduo, o qual se presta, muitas vezes, a crítico de sua própria obra, explicando e trazendo as verdades de seus textos, fundamentalmente calcados neles mesmos.

Para citar um exemplo próximo de nós, o teórico Karl Erik Schøllhammer identifica que o campo literário, no Brasil, esteve, durante um bom tempo - pelo menos desde a Geração de 30 -, interessado em conciliar o experimentalismo formal com o engajamento social, mas, no início do presente século - seu livro é de 2009 -, o escritor estaria sendo pressionado pelo excesso de realidade imposto pela mídia, o que frequentemente se traduziria em textos cada vez mais calcados em uma demanda pelo real:

Para os escritores da atualidade, a questão se recoloca [...] diante de um pano de fundo midiático caracterizado por uma grande demanda de realidade. O que mais interessa à mídia de hoje é a "vida real". Notícias em tempo real, reportagens diretas, câmera oculta a serviço do furo jornalístico ou do mero entretenimento, televisão interativa, reality shows, entrevistas, programas de auditório e todas as formas imagináveis de situação em que o corpo-presente funcione como um eixo. Na literatura, a situação não é muito diferente nem melhor: [...] o que mais se vende são biografias e reportagens históricas, confissões, diários, cartas, relatos de viagens, memórias, revelações de paparazzi, autobiografias e, claro, autoajuda. (SCHØLLHAMMER, 2009, p. 56).

Contudo, Sarlo nos alerta de antemão que não se trata de estabelecer regras para a ficção. Como ela mesma aponta, a própria história da literatura moderna é "um museu de transformações inesperadas" (SARLO, 2017) ${ }^{5}$. O que seu texto indica é que, no ato de sair de si, a pessoa que escreve pode acabar encontrando coisas mais interessantes, ou mesmo um outro. Diferentemente da poesia, onde o eu parece ter reinado com mais vigor, na ficção, houve uma época em que sentir o desligamento daquele que escreve com a história que se narra era algo digno de notabilidade. Joseph Warren Beach diria que o que mais impressiona na leitura de Fielding é o "desaparecimento do autor" (BEACH apud FRIEDMAN, 2002, p. 167). Se isso não acontece mais, se o desaparecimento do autor já não significa exatamente uma vitória, não caberia a Sarlo desdizer essa tendência, mas pensar sobre o que ela revela de tempos nos quais abrir a latinha do eu antes dos trinta anos não é errar.

Algumas perguntas se colocam, entretanto: como poderíamos definir em que circunstâncias a autorreferencialidade se justificaria? $\mathrm{Ou}$, ainda, o que ela pode implicar? Com tais questões em vista, valerá refletir sobre o caminho e a importância das memórias pessoais na literatura contemporânea. Segundo Julián Fuks, que leu o texto de Sarlo, se “[...] parece ganhar espaço uma nova atitude no campo das letras, entre centrais e periféricos, entre estabelecidos e marginais, entre veteranos e principiantes, entre acomodados e inquietos [...]", hoje, encontramos também

5 Tradução nossa. 
[f]ábulas sem um espaço fabular, sem construções cenográficas, fábulas de um tempo presente, fábulas cujo tempo está sincronizado com a própria escrita. Narrativas, por fim, em que o narrar avança sobre outros limites, o narrar testemunha, o narrar disserta, o narrar crítica, o narrar opina. (FUKS, 2017, p. 77-78).

Faz-se importante, então, pensar na função do relato centrado no próprio indivíduo, especialmente no terreno das memórias, com suas motivações e impactos específicos. Apesar das constatações que citamos serem pertinentes, o fato é que partem de uma avaliação que não leva em consideração a potência política da autorreferencialidade, esquecendo do lema do feminismo da década de 1970: "the personal is political". Em outras palavras, imaginamos que há sentido em pensar as experiências vividas e narradas pelos indivíduos como meio de tradução de questões maiores, para além do próprio sujeito, e de estabelecimento de conexões com outros planos, tal como a comunidade e a cultura. Como os estudos de Maurice Halbwachs (1990) mostraram, a memória é fruto das relações sociais dos indivíduos, de maneira que o que nós nos lembramos individualmente se constitui num contexto de coletividade, e vice-versa. Depois de um século caracterizado como "era dos extremos" (Hobsbawm), "era das catástrofes" (Seligmann-Silva), "era do totalitarismo" (Jesse), "era dos genocídios" (Cornelsen) e/ou "era do trauma" (Umbacht, Categari e Ourique) (CORNELSEN, 2014, p. 42), o relato de memórias pessoais toma contornos vitais para determinados indivíduos e suas coletividades.

\section{A IMPORTÂNCIA DA MEMÓRIA NA LITERATURA}

Memória e literatura possuem uma relação longa e complexa, mobilizando diferentes saberes, de maneira interdisciplinar. Rosani Ketzer Umbach, que também constata a "inundação" do mercado editorial nos últimos vinte anos com obras que abordam tal relação (Cf. UMBACH, 2008, p. 11), traz um pouco das maneiras como a memória se entrelaça com o universo literário, em uma perspectiva teórica. De acordo com a autora, há três correntes principais: 1) memória da literatura; 2) memória na literatura; e 3) literatura como 'veículo da memória coletiva'. A primeira, memória da literatura, diz respeito às obras literárias que lembram a sua própria tradição, evocando outras obras com as quais são capazes de estabelecer diferentes diálogos, numa chave intertextual e dialógica. Assim, temos a imagem da literatura como arquivo, como repositório de discursos passíveis de serem acessados e, por isso, reafirmados, emulados ou contestados. A segunda corrente, memória na literatura, concerne à representação da memória como faculdade humana, em textos literários, especialmente nos de ficção, em que é possível, por meio da plasticidade da forma, mimetizar o lembrar e o esquecer. Por fim, a terceira corrente - a que mais nos interessa aqui $\neg-$ é aquela em que se pensa a literatura como 'veículo da memória coletiva', quando os textos literários oferecem versões do passado histórico, no sentido de contribuir com a formação identitária das culturas em que estão inseridos (Cf. UMBACH, 2008, p. 12).

Tendo o século XX vivido uma concentração de eventos violentos, repressivos e, por isso, traumáticos, a literatura como veículo de representatividade para comunidades 
vítimas é empreitada que toma relevantes significações. Transmitir a experiência pode ser tanto um ato de disputa de memória, como Michael Pollak (1989) explicou, quanto de significação do sujeito, norteando e legitimando indivíduo e sociedade.

Segundo Umbach, essa função da tradição discursiva mnemônica como legitimadora - e até mesmo, se quisermos, de instrumento de disputa - se desenvolve a partir das teorizações de Walter Benjamin. Em suas Teses sobre o conceito da história, Benjamin pensa uma história em oposição ao discurso hegemônico, vendo no passado uma espécie de justiça para o presente. Segundo ele, a função do historiador estaria ligada à ação de recorrer à memória para impedir a conformação historiográfica que procura, constantemente, ratificar seus vencedores. A História, escrita em grande parte por uma classe dominante, estaria comprometida com uma continuidade violenta, capaz de agir arbitrariamente a favor de si própria, seja ocultando os rastros deixados por vozes antagônicas, seja as deslegitimando. Por isso, ao historiador caberia ler a história a "contrapelo", evocando o que fora reprimido, de modo a impedir a continuidade monolítica, uníssona, da História. Ao contrário da perspectiva segundo a qual a memória é ars, termo que evocaria a tradição retórica greco-latina, cujo foco seria a mnemoténica, pois se pensa o espaço memorialístico como armazenagem e técnica, a tradição benjaminiana vê a memória como vis, vigor ou força imanente, intimamente ligada à identidade. Trata-se de algo que nos lembram também Jacques Le Goff, ao destacar que a "memória é um elemento essencial do que se costuma chamar identidade, individual ou coletiva, cuja busca é uma das atividades fundamentais dos indivíduos e das sociedades de hoje, na febre e na angústia" (LE GOFF, 2013, p. 435, grifo do autor), e Joël Candau, ao dizer que "memória e identidade se entrecruzam indissociáveis, se reforçam mutuamente desde o momento de sua emergência até sua inevitável dissolução" (CANDAU, 2011, p. 19). Nas palavras de Umbach, é assumindo uma perspectiva teórica como essa "que o cultivo da memória, a conscientização sobre experiências passadas leva ao reconhecimento do presente e às mudanças necessárias para o futuro" (UMBACH, 2008, p. 20).

\section{MEMÓRIA NO CONTEXTO AFRICANO}

A visão sobre a história trazida por Benjamin encontra muitos locais de reverberação. Escrevendo sob a pressão de um governo nazista, que, pouco depois das Teses, iria levá-lo ao suicídio, o escritor construiu perspectiva historiográfica sui generis, que não se encerra apenas no seu tempo e espaço, servindo a outras experiências históricas, como aquelas próprias de contextos africanos, por exemplo.

Em grande medida, o colonialismo se fez seguindo o modelo para o qual Benjamin chamou a atenção: tem-se uma historiografia fabricada pelos vencedores, largamente utilizada para legitimar as investidas europeias sobre o continente africano. Textos de diferentes naturezas inscreveram as possibilidades epistemológicas, políticas e culturais que embasaram a subjugação dos africanos durante séculos. Edward Said corrobora esta ideia, ressaltando a importância da narrativa no processo de dominação: 
O principal objetivo de disputa no imperialismo é, evidentemente, a terra; mas quando se tratava de quem possuía a terra, quem tinha o direito de nela se estabelecer e trabalhar, quem a explorava, quem a reconquistou e quem agora planeja seu futuro - essas questões foram pensadas, discutidas e até por um tempo, decididas na narrativa. Como sugeriu um crítico, as próprias nações são narrativas. O poder de narrar, ou de impedir que se formem e surjam outras narrativas, é muito importante para a cultura e o imperialismo, e constitui umas das principais conexões entre ambos. (SAID, 2011, p. 11).

Para Said, a dimensão narrativa no processo colonial é ativa, de maneira que sua materialidade toma a mesma importância de fatores mais "brutos", como o militarismo, por exemplo. Basil Davidson também constata essa função narrativa em seu emaranhado de relações de dominação, contemplando a importância dos relatos em primeira pessoa feitos por colonos e sua tendência à construção do estereótipo africano, a partir do discurso europeu:

A literatura da exploração e conquista [da África] é tão vasta e variada quanto esses próprios processos. Mas, com raras exceções de vulto, os registros são elaborados apenas para uma atitude exclusiva de dominação: são os diários de homens que olham a África decididamente de fora. Não estou dizendo que se devia esperar outra coisa de muitos deles: o importante é que a qualidade de suas observações estava circunscrita a um campo restrito, e hoje devem ser lidas com essa ressalva. Se tentavam entender a mentalidade e as ações dos africanos que conheciam, era de passagem, e raramente. Quase todos achavam que estavam diante do "homem primevo", da humanidade tal como tinha sido antes de se iniciar a história, de sociedades que permaneciam na aurora dos tempos. [...] Esse ponto de vista caminhava a par da enorme expansão de poder e riqueza da Europa, com sua força política, sua flexibilidade e sofisticação, com sua crença de ser, de alguma maneira, o continente eleito de Deus. Pode-se ver o que pensavam e faziam os exploradores, sob outros aspectos respeitáveis, nos escritos de homens como Henry Stanley ou nas ações de homens como Cecil Rhodes e seus agentes de prospecção de minérios, prontos a se apresentar como honestos aliados de seus amigos africanos enquanto os tratados fossem cumpridos - os tratados por meio dos quais os governos ou interesses privados a que serviam e consolidavam podiam comprovar mutuamente a "ocupação efetiva". (DAVIDSON apud SAID, 2014, p. 171-172).

Em sua amplitude, as narrativas europeias estiveram a favor da colonização de diferentes maneiras, criando arcabouços teóricos pelos quais, científica ou retoricamente, foram explicadas e justificadas as violências perpetradas. Alguns o fizeram de forma mais remota, como Said demonstra ao falar de certos escritores europeus. Jane Austen, por exemplo, nunca escreveu uma dissertação sobre a hierarquia racial, mas seu Mainsfield Park não deixa de mencionar uma certa monocultura canavieira, no ultramar, para justificar o modo 
de vida da família Bertram. Outros foram mais direto ao ponto, como o filósofo Ernest Renan, quando, no ímpeto de naturalizar a hierarquia fundada na raça, afirma que "tudo correrá bem" se "cada qual" fizer "aquilo para que nasceu" (RENAN apud CÉSAIRE, 1978, p. 20). Aimé Césaire é contundente ao elencar os agentes do colonialismo:

Pois bem, camarada, serão teus inimigos - de maneira alta, lúcida e consequente - não só os governadores sádicos e prefeitos torcionários, não só os colonos flagelantes e banqueiros vorazes, não só trapaceiros políticos lambe-cheques e magistrados às ordens, mas similarmente e ao mesmo título, jornalistas biliosos, académicos de papada endolarados de idiotices, etnógrafos metafísicos e dogonneux, teólogos farfalhudos e belgas, intelectuais gárrulos, saídos a tresandar a coxa de Nietzsche ou dervixes-filhos-de-rei chutados de não sei que Plêiade, os paternalistas, os beijoqueiros, os corruptores, os distribuidores de palmadas nas costas, os amadores de exotismo, os divisionistas, os sociólogos agrários, os adormecedores, os mistificadores, os caluniadores, os embusteiros e, duma maneira geral, todos aqueles que, desempenhando o seu papel geral, todos aqueles que, desempenhando seu papel na sórdida divisão do trabalho para o bem-estar da sociedade ocidental e da burguesia, tentam, de maneira diversa e por diversão infame, desagregar as forças do Progresso - com o risco de negar a própria possibilidade do Progresso - todos sequazes do capitalismo, todos suportes declarados ou envergonhados do colonialismo rapace, todos responsáveis, todos execráveis, todos negreiros, todos credores, de futuro, da agressividade revolucionária. (CÉSAIRE, 1978, p. 39-40).

Davidson chama a atenção para o relato de viagem dos colonos. Suas memórias também seriam grande receptáculo de justificativas que teriam dominado a perspectiva histórica. Ao escrevê-las, os conquistadores elevavam seus próprios feitos e controlavam a narrativa do que acontecia nas terras distantes. Tal prática, todavia, encontra empecilhos, na medida em que a perspectiva dos próprios africanos passa a disputar lugar e a contradizer os paradigmas ocidentais. M’Bokolo, ao falar sobre a assunção do "ponto de vista africano", enfatiza a importância que passam a adquirir "as resistências à conquista colonial", as quais, conectadas com os "momentos fundadores do nacionalismo africano" retiram "à intrusão colonial [...] os adornos épicos e míticos que a revestiam” (M’BOKOLO, 2007, p. 321).

A desmistificação do relato dominante é um dos efeitos da fortificação da narrativa marginal. Outras versões do passado surgem para disputar espaço de validade e colocar em primeiro plano sujeitos que, a princípio, não tinham centralidade ou agência. A libertação das colônias africanas possibilitou também a inserção dos países em circuitos artísticos e científicos globais, que se fortaleceram com a difusão dos meios de comunicação e de trânsito. A descentralização de poder contribuiu para o empoderamento de novos sujeitos. Hoje, o cinema indígena, a literatura do chamado Terceiro Mundo e a filosofia africana, para citar alguns exemplos, encorpam a todo vapor e florescem a partir de uma institucionalização e capitalização mais larga e menos hierárquica, muito embora isto não signifique a horizontalidade do jogo de forças inerente nestes e em outros campos da cultura. 
Não só a desmistificação e a revisão da memória são importantes, mas também a fortificação das sociedades e de seus indivíduos o são nesse processo. $\mathrm{O}$ aclamado escritor queniano Ngũgĩ wa Thiong’o alerta para o devir de uma Renascença Africana. Trata-se de uma Renascença oposta à Renascença Europeia, mas que também é marcada pela junção de fatores que tornam possível uma virada histórica. São palavras do autor:

[...] o renascimento africano já começou: começou no momento histórico em que a ideia de África se tornou uma força organizadora, em oposição aos impérios coloniais europeus. V. Y. Mudimbe descreve a ideia de África como um produto do sistema de auto-representação do Ocidente, que incluía a criação de uma alteridade concebida e transmitida por sistemas conflitantes de conhecimento. Mas prefiro pensar na ideia de África - ou, mais apropriadamente, na "ideia africana", como uma auto-representação africana. Para distingui-lo da fórmula mudimbeista segundo a qual a Europa se encontra através de sua invenção da África, vejo a ideia africana como a que foi forjada na diáspora e viajou de volta ao continente. (THIONG'O, 2009, p. 72) .

Thiong'o defende este quadro de construção da imagem africana, mas coloca no centro dele o papel da memória. Em suas palavras, a "relação dos escritores com sua memória social é central para sua busca e missão. A memória é o que liga o passado e o presente, o espaço e o tempo, e é a base dos sonhos. Escritores e intelectuais [...] estão cientes de que sem uma religação com a memória africana não há esperança” (THIONG’O, 2009, p. 39) ${ }^{7}$. Para o autor, que também acredita nas narrativas como espaço de confrontação, os africanos foram desmembrados (dismembering) no processo de colonização, ao qual reagem, em particular, com a "imaginação criativa", que considera uma das maiores "práticas de recordação” (re-membering practices) (THIONG’O, 2009, p. 39) ${ }^{8}$.

Como nas histórias de Waiyaki wa Hinga, importante figura da resistência colonial no Quênia, que foi enterrado vivo com a cabeça virada para baixo - algo que ia contra os rituais locais, os quais determinavam que a cabeça deveria apontar para o Monte Quênia -, e do rei Hintsa, dos Xhosa, cuja cabeça fora cortada e levada para o Museu Britânico (Cf. THIONG'O, 2009, p. 3), africanos viram suas instituições, línguas, costumes e símbolos culturais serem amputados e substituídos por outros, externos a eles. Para recosturar (re-membering) esse corpo, a memória desempenha um papel central, reconectando o sujeito com a história de sua própria vida e com sua cultura. O relato em primeira pessoa é ressignificado, passando a ser mais do que mera expressão narcísica. Torna-se, de fato, a construção individual de um devir coletivo.

\footnotetext{
6 Tradução nossa

7 Tradução nossa.

8 Tradução nossa.
} 


\section{SONHOS EM TEMPO DE GUERRA}

Nome de peso no campo da literatura africana e dos estudos pós-coloniais, Ngũgĩ wa Thiong'o nasceu no Quênia, em 1938, e é autor de um robusto conjunto de obras. Um ano depois da independência de seu país de origem, em 1963, publica seu primeiro romance, dando início a uma produção intelectual longa, que, recentemente, agrega a trilogia de memórias, com os títulos de Dreams in a Time of War: A Childhood Memoir (2010), In the House of the Interpreter: A Memoir (2012) e Birth of a Dream Weaver: A Memory of a Writer's Awekening (2016).

Apenas o primeiro volume conta com tradução para o português, com o título de Sonhos em tempo de guerra (2015). Nele, Ngũgĩ wa Thiong’o narra sua infância e adolescência na zona rural de Limuru, onde começou sua jornada para se tornar escritor, superando todas as adversidades impostas a uma colônia britânica da África, em vias de conflito por sua libertação. O caminho do autor não se faz em uma linha reta. Escrito num tom que nos lembra os romances de formação (Bildungsroman), Thiong'o nos propõe uma experiência dupla,que pode ser lida tanto em chave romanesca quanto documental, e na qual acompanhamos a formação de uma criança e de uma nação. As reflexões pessoais - em construção, uma vez que o narrador está criando sua superfície de contato consigo e com o mundo - e as descrições dos elementos externos - também cambiantes, numa nação que parece "trocar de mão" rapidamente, em meio a muitos conflitos - se combinam e se evocam mutuamente. Como Jennifer Muchiri sugere, a narrativa não apresenta "meras marcas e registros da história, mas ganha significado pessoal e adquire um rosto humano" (MUCHIRI, 2014, p. 89) ${ }^{9}$, manifestando-se os traços específicos do tempo e do espaço queniano no rosto que se desenha.

Filho da terceira esposa de uma família poligâmica de quatro mulheres, um homem e vinte e quatro filhos, Ngũgĩ via na educação, assim como muitos de seus contemporâneos, uma porta para fugir da pobreza e dos conflitos nacionais. Ao contar o perseguir desse sonho, o autor contempla camadas das tradições locais e da história política colonial do Quênia, que assistia aos primeiros confrontos da resistência Mau Mau com o governo britânico, enquanto as sombras das Guerras Mundiais ainda pairavam sobre o país.

Depois de ter sua mãe expulsa da casa do pai, Ngũgĩ vai para a casa dos avós. É o tempo de personalidades revolucionárias, como Jomo Kenyatta e Mbiyũ Koinange, e do início da repressão colonial. Certa noite, alguns homens influentes da região das terras de seu avô são presos e executados sumariamente. O autor narra como o evento, índice das movimentações políticas locais, perpassa sua vida e modifica suas perspectivas:

O terror se abateu sobre nossa região, mas atingiu meu avô com mais força. Ele era o pai de criação de Kimũchũ [um dos assassinados na ocasião]; eram muito próximos. Meu avô estava convencido de que seria o próximo, que "eles" iriam buscá-lo à noite. Ele buscou abrigo na cabana da minha mãe. Toda noite, sob o véu das trevas, ele se esgueirava para a nossa casa. Ver aquele homem tão pode-

9 Tradução nossa. 
roso, o latifundiário respeitado e tutor de um subclã, sim, meu avô, que escrevia cartas para o governo, em nossa cabana, tremendo de medo do desgoverno colonial, foi minha primeira percepção real da seriedade do estado de emergência. (THIONG'O, 2015, p. 158).

A estrutura das escolas, com instituições assimiladas (kikore) e autônomas (kariga), revela a cisão política em curso, enquanto os traços locais, como a oralidade, a poligamia, a alimentação e os ritos de passagem, fazem-nos imergir num universo cultural específico. Ngũgĩ descreve todo o processo de se tornar homem, com a tradição da circuncisão, dando ao leitor a oportunidade de vislumbrar a complexidade do processo e seu fundamento, naquela cultura. O narrar da lembrança também é reflexivo e recai sobre o autor no presente da escrita:

Embora todo o rito de me tornar homem tenha deixado uma impressão profunda em mim, saio dessa experiência ainda mais convencido de que, na nossa época, educação e aprendizado, e não uma marca na carne, representam o caminho de se dar poder a homens e mulheres. (THIONG'O, 2015, p. 195).

Sonhos em tempo de guerra capta uma perspectiva da história colonial queniana experienciada por um sujeito específico. As memórias de infância se transformam em um receptáculo significador de uma identidade pessoal e política, interligando sujeito e território por meio da identificação. A recriação do passado não muda o curso dos eventos, porém, traz novas perspectivas, que influenciam nas decisões do futuro, tanto do sujeito que escreve, quanto para a historiografia a qual se liga. O ato de lembrar reclama sua centralidade. Superando o caráter narcísico de certos relatos em primeira pessoa, as memórias pessoais se conectam intimamente com a construção de um passado próprio, oposto ao passado inventado por outros para uma coletividade que se via de fora. É a partir do relato da experiência vivida, em demanda por um real que se esconde nas malhas de narrativas forjadas pelo imperialismo, que sujeito e nação são capazes de se fortalecer e construir um novo caminho, longe dos estigmas do passado e da tentativa de apagamento dos seus rastros. 


\section{REFERÊNCIAS}

M’BOKOLO, Elikia. África negra história e civilização: tempos e espaços africanos. Trad. Alfredo Margarido. Lisboa: Vulgata, 2007. [Tomo I - até ao século XVIII].

CANDAU, Joël. Memória e identidade. São Paulo: Contexto, 2011.

CÉSAIRE, Aimé. Discurso sobre o colonialismo. Trad. Noémia de Sousa. Lisboa: Sá da Costa, 1978.

CORNELSEN, Elcio Loureiro. Literatura, cinema e violência: imagens do genocídio em Ruanda. In: SARMENTO-PANTOJA, Tânia. (Org.) Arte como provocação à memória. Curitiba: CRV, 2014, p. $41-72$.

FRIEDMAN, Norman. O ponto de vista na ficção: o desenvolvimento de um conceito crítico. Revista USP, São Paulo, n. 53, p. 166-182, 30 mai. 2002.

FUKS, Julián. A era da pós-ficção: notas sobre a insuficiência da fabulação no romance contemporâneo. In: DUNKER, Christian et al. Ética e pós-verdade. Porto Alegre; São Paulo: Dublinense, 2017, p. 75-93.

HALBWACHS, Maurice. A memória coletiva. Trad. Laurent Léon Schaffter. São Paulo: Edições Vértices, 1990.

LE GOFF, Jacques. História e memória. 7. ed. Trad. Irene Ferreira et al. Campinas: Unicamp, 2013.

MUCHIRI, Jennifer. The Intersection of the Self and History In Kenyan Autobiographies. Eastern African Literary and Cultural Studies, Nairobi, v.1:1-2, p. 83-93, 2014.

PAIVA, Marcela Ribeiro Pacheco. Entre a memória e a ficção: autoficção. RevLet - Revista Virtual de Letras, Jataí, v. 08, n. 01, p. 630-640, jan/jul, 2016.

POLLAK, Michael. Memórias, esquecimento, silêncio. Revista Estudos Históricos, Rio de Janeiro, v. 2, n. 3, p. 3-15, 1989.

SAID, Edward W. Cultura e imperialismo. Trad. Denise Bottman. São Paulo: Companhia das Letras, 2014.

SARLO, Beatriz. Encerrar el yo en una lata. El País, Madrid, 27 ago. 2017. Disponível em: <https:// elpais.com/cultura/2017/08/28/babelia/1503928864_171902. html>. Acesso em: 4 nov. 2019.

SCHØLLHAMMER, Karl Erik. Ficção brasileira contemporânea. Rio de Janeiro: Civilização Brasileira, 2009. 
THIONG’O, Ngũgĩ wa. Something Torn and New: an African Renaissance. New York: Basic Civitas Books, 2009.

Sonhos em tempo de guerra: memórias de infância. São Paulo: Biblioteca Azul, 2015.

UMBACH, Rosani Úrsula Ketzer. Memórias da repressão e literatura: algumas questões teóricas. In: . (Org.). Memórias da repressão. Santa Maria, RS: UFSM, PPGL-UFSM, 2008, p. 11-20. 